\title{
Special Series: Research on Teaching Physical Education in the Age of COVID-19
}

The COVID-19 pandemic has created many hardships for people all over the globe. During the past 13 months, teachers and schools have been forced to "pivot" and restructure their teaching approaches to accommodate virtual, hybrid — and, eventually, faceto-face teaching/learning with social distancing measures. While no teachers of any subject found this to be an easy task, given the nature of the subject matter content, physical education teachers were chief among those who had the greatest challenges when forced to alter the delivery of their classes.

As expected, a calamitous situation like this prompted a group of researchers to investigate the nature of teaching physical education in the age of COVID-19. While there are, perhaps, a number of researchers around the world engaged in this type of scholarship, JTPE was approached by Drs. Erin Centeio and Collin Webster with a proposal for a "Special Issue" featuring a series of studies in which they and many other colleagues were engaged. The incoming Editor-in-Chief, Heather Erwin, and I recognized the timeliness and importance of the topic but were faced with a slight backlog of manuscripts to publish which included a previously accepted "Special Issue" slated to appear in late 2021.
After some discussion and brainstorming, the idea of a "Special Series" became a possible solution. To our knowledge, a "Special Series" had not been included in the previous volumes of JTPE, so we created one. This issue is the first of three that will feature two peer-reviewed articles focusing on Research on Teaching Physical Education in the Age of COVID-19. As is the process with a "Special Issue" or a Monograph, Drs. Centeio and Webster served as Guest Associate Editors in addition to soliciting and even authoring some of the manuscripts for the "Special Series."

While the notion of a "Special Series" is not expected to become the norm for JTPE, the gravity of the times dictated that this was the right thing to do. Many thanks to JTPE's Managing Editor, Crystal Robinson, for helping get this idea off the ground and approved by Human Kinetics.

I hope that the JTPE readership will find the "Special Series" an informative and thought-provoking addition to the last three issues of Volume 40.

Bryan McCullick, Editor-in-Chief 